\title{
História, religião e arte
}

\author{
VICTOR KNOLL
}

RESUMO: As preocupações teóricas de Hegel durante o seu período de formação envolveram a Aufklärung, as relações entre a razão e a religião e eventos ético-políticos. Quanto a estes últimos, as referências fundamentais foram a vida pública da Grécia clássica e as transformações pelas quais passava a Europa, em particular a Revolução Francesa. As múltiplas relações e implicações dessas preocupações teóricas durante o referido período envolviam uma aproximação entre a história e a religião. A reflexão estética hegeliana encontrou no âmbito dessa aproximação o embrião de suas concepções sobre a arte. Além disso, a arte se apresentou como uma feliz manifestação dos liames que Hegel via entre a história e a religião.

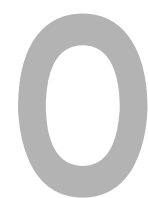

contexto histórico no qual se deu a fermentação do sistema hegeliano atuou de modo peculiar, já desde os trabalhos da juventude, para a orientação assumida por seu pensamento: pós Kant, companheiro de Schelling, à sombra de Fichte, interlocutor de Hölderlin, recomendado por Goethe. Costuma-se dizer - conforme vocabulário do próprio Hegel - que o Idealismo Alemão bem como o Romantismo são "movimentos" ou "etapas" que nele culminaram, e, por isso mesmo ali reconhecemos o palco de sua atuação teórica. É certo que, de modo geral, pode-se lembrar os estreitos compromissos entre o Idealismo e o Romantismo enquanto rubrica histórica e reconhecível particularmente no que diz respeito às artes. As linhas mestras desta cena mostram também o subsolo das preocupações do Hegel anterior à Fenomenologia em relação ao sentido das manifestações artísticas. Temos aí dois pontos para nossa consideração: de um lado, o trabalho filosófico que atuava diretamente em seu período de formação: Fichte e Schelling; de outro, a atmosfera intelectual então reinante
UNITERIMOS: história, religião, razão, arte.
Professor do Departamento de Filosofia da FFLCH-USP 
na Alemanha e, talvez, a melhor referência seja Hölderlin ao lado de Goethe. A relação pessoal desses dois ícones do Romantismo com o filósofo - o peso que tiveram em sua biografia intelectual - já é um bom motivo para suspeitarmos da influência deles nas suas futuras concepções estéticas. Assim, se de um lado podemos pressentir que a elaboração do pensamento hegeliano teve muito a ver com os românticos, de outro o sistema acabado faz frente a importantes posições assumidas por aquele movimento, como por exemplo a concepção de uma comunhão entre o Espírito e a Natureza. Pode-se dizer que Hegel, em sua formação, soube colher e lidar com as implicações filosóficas do Romantismo e soube levá-las à plenitude teórica e crítica. Entretanto, se recorrermos às classificações ofertadas pela historiografia, podemos também dizer que Hegel representa uma síntese dos espíritos clássico e romântico.

É também lugar-comum entre os comentadores de Hegel referir as relações de aproximação e depois de distanciamento que seu pensamento já maduro mantém com Fichte e Schelling. Assim, as questões freqüentemente atacadas dizem respeito à filosofia da identidade, à filosofia da reflexão, aos aspectos materiais e formais da doutrina da ciência e, mais uma vez, às relações entre o Espírito e a Natureza. Aqui não nos interessa retomar - ou simplesmente repetir - as filiações e sobretudo as diferenças "técnicas" entre esses autores. Tomamos como um dado o repertório já existente sobre aqueles pontos, tal como o encontramos - para citar alguns exemplos - em Hyppolite, Jean Whal, Kojève, Dilthey, Hartmann e Bourgeois. Importa-nos antes deter uma visão, conforme já dissemos, do palco histórico no qual Hegel atuou. Três itens se destacam: 1- as relações com o Idealismo alemão enquanto movimento histórico-filosófico, 2- as relações com a Aufkärung e o problema religioso e 3- as relações com a Revolução Francesa.

A sequiência Kant-Fichte-Schelling-Hegel remonta ao próprio tempo de Hegel e, de maneira pontuada, foi estabelecida por ele próprio na última seção de sua História da Filosofia quando trata da "novíssima filosofia alemã". A postulação dessa seqüência põe a questão da origem do sistema e da filiação de Hegel. Dilthey observa que há uma certa razão nessa formulação. Do ponto de vista do desenvolvimento da história da filosofia moderna pode-se surpreender uma passagem de um autor para outro. Essa seqüência forma um "movimento" histórico no qual se pode vislumbrar uma coerência. Entretanto, importa distinguir entre um possível relacionamento filosófico e uma filiação histórica propriamente dita.

Embora na Jena de 1801 tenha se declarado discípulo de Schelling, o ponto de partida de Hegel - do Hegel da Lógica e da Enciclopédia -, antes de o procurarmos em Kant, Fichte ou no próprio Schelling, nós o encontramos nos estudos históricos sobre a Grécia e o Cristianismo. Foi a partir desses estudos que Hegel abandona a preocupação com a teologia e se aproxima da filosofia. Talvez, por se ter declarado discípulo de Schelling - ainda o "jovem Hegel" - e por fazer corpo com o Idealismo, a sequiência Kant-Fichte-SchellingHegel tenha conquistado cidadania na história da filosofia moderna e é tida 
como um dado. Sem dúvida há relacionamento filosófico, mas a filiação histórica deve ser posta em outros termos. A origem de sua reflexão - que o conduziu para o sistema - repousa numa reflexão sobre a História e a Religião.

Em favor de uma coerência na compreensão da história da filosofia moderna aceitamos - e trata-se de algo já enraizado - a sequiência Kant-FichteSchelling-Hegel, que, conforme apontamos, remonta ao próprio Hegel. Contudo, em favor dessa mesma compreensão é preciso considerar o que o Hegel histórico arrancou não de Kant, não de Fichte, não de Schelling, mas de uma reflexão sobre a História. É reconhecimento líquido que teve sob seus olhos os textos de Kant, de Fichte e de Schelling. Temos aí um relacionamento filosófico e não a "motivação" do sistema.

Dilthey observou que Hegel ainda jovem adotou o ponto de vista kantiano para, a título de exercício, analisar as origens do Cristianismo. Em A Vida de Jesus não há propriamente um compromisso, mas um aprendizado. "Em nenhum momento de seu desenvolvimento foi fichteano ou schellingniano e junto às influência de Fichte prevaleceram também outras muito diferentes”(Dilthey, 1956, p. 45). Os grandes nomes da história da filosofia são discípulos uns dos outros na medida em que os sistemas se completam ou porque um autor retoma questões pendentes em outro. É o caso de Spinoza que retoma a questão das relações entre a alma e o corpo que permanece aberta em Descartes; aqui, na seqüência apontada, vê-se uma "complementaridade" de quadros conceituais.

Note-se que a obra de juventude de Hegel mostra, antes de mais nada, a originalidade de seu itinerário; as interrogações primitivas de Hegel não são as mesmas de Kant, de Fichte ou de Schelling. De um lado, temos o peso de sua formação básica em teologia ao mesmo tempo em que estava atento aos eventos históricos de seu tempo e, de outro, há que lembrar a sedução que sobre ele exerceu a descoberta da Grécia antiga, compartilhada com seu amigo Hölderlin. Aí está o embrião de uma futura concepção da arte que irá conciliar a manifestação do sentimento religioso pela arte, a arte como expressão das comunidades e a estatuária grega como manifestação da perfeição artística.

Há ainda um outro ponto: Häring nos faz notar que para compreender Hegel é necessário estudar o seu vocabulário e a sua técnica de expressão. Essa preocupação é importante para a compreensão da origem e filiação de um sistema. E a linguagem de Hegel é peculiar.

Durante o período de Tübingen, Hegel possuía concepções em comum com Schelling, mas as fontes e as inspirações dessas concepções eram diferentes. Isso torna-se patente a partir da consideração de seus textos de juventude. No prefácio à Fenomenologia do espírito é declarado o rompimento. Além dos autores já listados, costuma-se ver também alguma influência de Schiller e Hölderlin, que o Hegel maduro soube transformar em favor de seu próprio pensamento. Por outro lado, Jean Hyppolite indica que a evolução 
do pensamento de Hegel é marcado por preocupações religiosas. Temos aí as relações que o nosso autor mantém com a Aufkärung. Mais tarde, no Hegel maduro, as manifestações religiosas irão constituir a razão das obras de arte.

Hegel permaneceu em Tübingen entre os anos de 1788 e 1793 como estudante de Teologia Luterana. Por aquele tempo os teólogos se defrontavam com uma forte tendência de racionalizar a religião. O estudo da Teologia e tal tendência da época repercutiram fortemente em Hegel. Temos aí os efeitos da Aufkärung sobre os estudos teológicos. De fato, em relação aos assuntos tratados pela teologia, a Aufkërung defendia uma posição de caráter racional. O movimento defendia o abandono de todo aspecto sobrenatural no que se refere às coisas da religião. Por seu turno, conforme já vimos, o interesse de Hegel está voltado para o social e o histórico; por exemplo, procura compreender como o cristianismo se impôs ao paganismo. Hegel está preocupado com o acontecimento, com o dar-se da história. O sobrenatural, o milagre, a revelação - enfim, os problemas propriamente teológicos - já não mais se constituem como "problemas", isto é não mais constituem o objeto de interesse de sua reflexão. Hegel se assume como um Aufklärer. O universo artístico se constituía como uma porta aberta para tal posição.

Essas observações indicam a origem e a filiação do pensamento de Hegel. Os elementos históricos são muito mais importantes para a compreensão da "montagem" do sistema do que aqueles advindos dos quadros conceituais de Kant, Fichte ou Schelling. É óbvio que Hegel trabalhou os seus temas com elementos provenientes desses quadros conceituais, mas o seu ponto de partida está na consideração das ocorrências históricas de seu tempo e no estudo do evolver da História Universal.

O lugar que Hegel ocupa no interior do Idealismo Alemão - e sobretudo os vínculos que com ele mantém -, traz a questão das relações desse movimento com as filosofias anteriores. O idealismo procura, particularmente, dar uma resposta ao ceticismo inglês. Trata-se do elo formado por Hume-Kant. De um lado, temos a posição de Hume que sustenta que não há princípios universais necessários. Tal posição irá refletir-se na moral: os princípios morais são produtos dos costumes e das sociedades. $\mathrm{O}$ âmbito da vida moral é o relativo. Devemos nos conformar aos costumes dados. Já Kant afirma a existência de princípios absolutos, universais e necessários. Há uma Razão Prática. Três pontos governam a Razão Prática e dão expressão ao caráter absoluto, universal e necessário da lei moral: o imperativo categórico, a existência de Deus, a imortalidade da alma. O esforço de Kant para instaurar o império da Razão no mundo moral encontra o seu acabamento em Hegel. Catalisando a atitude teórica do Idealismo - e se constituindo no seu acabamento -, procura salvar a Razão pela História. Traz o valor da Razão para o âmbito da experiência efetiva. A História é uma manifestação da Razão. Por seu turno, a História tem no sentimento religioso uma de suas grandes alavancas.

Sem dúvida, estamos numa época na qual as maiores preocupações 
centralizam-se no problema da razão ou na atribuição à razão de um papel decisivo no governo do mundo. Aufkärung na Alemanha, Iluminismo na França. O racionalismo, ultrapassando os limites da ciência ou da teoria do conhecimento, invade todos os âmbitos da experiência humana. De modo privilegiado, a ética e a política. $\mathrm{O}$ racionalismo, sob a roupagem agora do Iluminismo, reflete uma necessidade histórica: a ascensão da burguesia. Spinoza já houvera preparado o terreno na Holanda progressista do século XVII ao publicar, em 1670, o seu Tratado teológico-político. A partir desse momento surge uma nova concepção de razão, assumida e desenvolvida pela Aufkärung, e aprofundada por Kant, Fichte e Schelling. Nessa perspectiva histórica surge a figura de Hegel. Entretanto, há que advertir que o sistema de Hegel não é apenas o resultado de condições histórico-sociais, mas é parte integrante e ativa dessa situação histórico-social. Estamos diante de um processo de mútua dependência.

De resto, conforme observávamos mais acima, outro elemento histórico presente na formação de Hegel é a sua relação com a religião, iluminada pela Aufklärung. Hegel estuda teologia luterana precisamente no momento em que o ponto de vista da Aufklärung sobre religião chega às suas últimas consequiências. As suas disposições teóricas atuam e influenciam os meios religiosos. Logo em seguida os ortodoxos procuram manifestar uma reação contra a racionalização da religião. De seu lado, a Aufklärung assume progressivamente uma desmedida confiança na razão. Para alguns, mais críticos, tal confiança é vista como ingenuidade. $\mathrm{O}$ exemplo mais marcante é o de Leibniz: o otimismo da razão. Objeto do sarcasmo de Voltaire.

A razão é guinada à maior dignidade. A verdadeira luz deriva da razão e não da revelação. O maior inimigo da humanidade é a ignorância, a carência da razão. "A luz que vai iluminar a rota da nova humanidade é a luz da razão [...]. Os inimigos a combater são a ignorância, o prejuízo, a superstição" (Asveld, 1953, p. 12-13). Assim, articula-se o império de razão. Já na Aufklärung o valor atribuído à razão depositou a semente da identificação do racional com o real. E aí temos o grande lema do futuro Hegel. Aquilo que não é interpretável ou apreensível pela razão é posto de lado. A Aufklärung denuncia, ao mesmo tempo, a intolerância da Igreja ortodoxa e a aliança entre o trono e o altar. Tal aliança somente poderia ser mantida pela autoridade, vale dizer pelo autoritarismo. Na Alemanha, de maneira lenta, ao longo do século XIX, os efeitos do "pensado" se tornariam presentes.

Dentro desse cenário a Aufklärung procurou operar uma eliminação de todos os dados irracionais da vida religiosa e, assim, a Religião ficou reduzida a três pontos: "Este trabalho progressivo de eliminação resultou finalmente na redução das idéias religiosas a três idéias racionais de Deus, da liberdade ou da moral, e, da imortalidade, assim como à redução correspondente do religioso ao moral" (Asveld, 1953, p. 14). Estava preparado o quadro para a compreensão que o mundo da arte sempre manteve com a vida religiosa ao lhe dar expressão por meio dos rituais, da música e da figuração. Agora, tais 
vínculos estavam iluminados pelo sol da razão. Tais vínculos podiam ser reconhecidos como verdadeiros. Muito antes da elaboração da Estética como sistema, ao longo da primeira metade da primeira década do século XIX, Hegel assume essas relações entre arte e religião; em 1807 estão firmadas na segunda parte da Fenomenologia do espírito.

Para a Aufklärung a virtude não estava vinculada e nem era dependente de alguma recompensa. A exigência de virtude não envolvia prêmios. A virtude detinha um valor por si mesma. Tal era a regra do dever. Nesse momento, o homem faz uma homenagem racional a Deus. Mesmo a imortalidade - que é aceita - é articulada por um discurso racional. Tal atitude, que assume uma fisionomia filosófico-religiosa, caracteriza o Deísmo. Esta noção aplica-se à religião natural, isto é, à doutrina dos filósofos que admitiam apenas a existência de Deus, a imortalidade da alma e a regra do dever, e que rejeitavam os dogmas revelados e o próprio princípio de autoridade em matéria religiosa (Lalande, 1956, p. 213-214). Compreende-se, portanto, porque a Aufklärung denuncia a intolerância e a aliança entre o Estado e a Igreja. Tais são os pontos de atuação da teologia Luterana no que concerne ao exercício da religião e, em continuidade, racionaliza-se por esse caminho; entretanto, a teologia Luterana se distancia da Aufklärung na medida em que conserva a revelação. Esses dois lados, que põem um conflito, preocupam o jovem Hegel. Razão e revelação: termos que devem encontrar um espaço de convivência. De imediato, as produções artísticas ofereciam a solução para tal conflito.

Mas, de fato, inspirada em Wolf, a teologia da época é de índole racionalista. Assim, diante das exigências da razão, os teólogos procuram salvar a religião pela distinção do par "natural" " "sobrenatural". Dos dois termos, eliminam o antinatural ou seja, o sobrenatural - o demônio, o pecado original, etc. - porque anti-racionais. Assim, no início do século XIX, fez-se na Alemanha uma história e uma crítica aos dogmas, segundo as quais a Igreja Cristã e sua teologia representavam uma degenerescência em relação ao cristianismo antigo. Ora, precisamente, esse cristianismo antigo coincidia com a religião natural ou racional. Surgiu daí não só no meio intelectual, mas, também, no seio da sociedade alemã uma espécie de ressentimento contra toda a história da Igreja. A dogmática passou a ser entendida como o afastamento da humanidade da religião natural. Sabe-se que Hegel participou desse ressentimento. A religião grega, expressa por meio da estatuária, é uma referência para ser levada em conta.

Por força desse quadro, Hegel assume uma nova estratégia em relação ao problema religioso; muda de posição em relação à teologia. Assume a posição da História. Passa a pôr em primeiro lugar a ocorrência histórica. Hegel não volta o seu olhar para a figura do Cristo, mas para a própria história do Cristianismo, que é compreendida como uma necessidade na dialética do desenvolvimento da História Universal. De resto, há que lembrar sempre os fortes compromissos da cultura alemã - no que diz respeito aos hábitos, 
usos e costumes - com o Protestantismo.

A Reforma, ao ter plasmado a maneira de ser do povo alemão ao longo dos tempos modernos, sedimentou em seu pensamento a noção de liberdade. Tal noção ganha corpo no interior da Aufklärung. Da ótica Protestante a liberdade é um valor pessoal, íntimo, independente da posição do indivíduo na sociedade. Enquanto a Igreja Católica atua no sentido de desempenhar um papel mediador, no Protestantismo o homem está imediatamente diante de Deus. A liberdade se aloja no íntimo da pessoa; a liberdade social é considerada como algo de indiferente à essência do homem. Compreende-se por que, graças a essas disposições religiosas configuradas pelo Protestantismo, a classe intelectual afasta-se das coisas práticas. Assim, o intelectual irá procurar uma realização na arte, na ciência, na filosofia, na religião. Nesse clima formou-se a cultura Idealista. Desde o pietista Kant até o Hegel estudante de Teologia, junto com Hölderlin e Schelling em Tübingen. Entretanto, há que salientar a seguinte circunstância: preocupavam-se mais com a idéia de liberdade do que com a sua efetivação. Mas, no cerne daquela preocupação estavam os laços entre a história e a religião que desde cedo Hegel se deu conta de sua expressão sensível por meio das artes. A arte acompanhou a evolução do Espírito ao longo da história universal.

É preciso considerar, assumindo outro ponto de vista, que o Idealismo é apenas em parte um resultado do Protestantismo. A burguesia alemã, que não se desenvolveu como a francesa e a inglesa, apenas "pensava" na liberdade. O burguês francês ou inglês realizava o que o alemão pensava. De fato, os franceses e os ingleses procuravam efetivar a idéia de justiça. Enquanto isso, os alemães falavam em moralidade.

A necessidade de instaurar a justiça assume proporção jamais vista nos tempos modernos. A falta de justiça leva às reivindicações, seja no âmbito social, seja no privado. De imediato a Revolução Francesa vem atender tal apelo. Na Alemanha não houve uma "Revolução Francesa". Quando não se realiza o justo, realiza-se o moral. Hegel instaura o seu sistema como expressão de um Idealismo, dentro da cultura alemã, que procura superar a ausência do efetivo, do real. Conforme já indicamos, é dentro desse quadro que Hegel se preocupa com o "dado vivido". E esse é o motivo do "dado vivido" ser uma exigência do próprio sistema. Assim, Hegel encontra na História, no dar-se histórico, o seu grande manancial. Esta é a outra via que assegurou à arte extraordinária importância no interior do sistema. A arte ocupa-se com o vivido. Nela temos a explosão do Phatos de uma comunidade e de uma época. Já o jovem Hegel intuía que a arte se constituía como o veículo da história sobre os trilhos da religião.

Compreende-se, a partir dessas observações, que a Revolução Francesa se constituiu na Alemanha como um estímulo ao pensamento; há quem tenha dito que chegou a perturbar a "serenidade Kantiana". Certamente vibrou no espírito do jovem Hegel. Pode-se dizer que a obra de emancipação do indivíduo, iniciada pela Renascença e pelo Protestantismo, encontrou o 
seu acabamento na Revolução Francesa. Desde logo passa a ocupar a reflexão de Fichte e de Schelling, na medida em que passa a ser possível pensar um Estado em termos racionais. De resto, embora lugar-comum, há sempre que levar em conta que a Revolução Francesa vem realizar os ideais da burguesia. Em Tübingen, Hegel segue apaixonadamente os passos da Revolução e a caracteriza, em um primeiro impulso, como uma época de transição. Já nesse momento está no espírito de Hegel o reconhecimento de uma "razão" imanente aos movimentos sociais. A burguesia desempenha um papel "racional" na história. Mais ainda, aí temos o embrião do reconhecimento, no plano do sistema, da Razão ligada ao desenvolvimento da sociedade, e mesmo, constituindo-se no seu governo. Embora a sociedade alemã - lembremos mais uma vez -, em relação à inglesa, à francesa e à holandesa, estivesse "atrasada", a Razão do século XVIII expressa uma classe que quer se impor e tem consciência de si. Conforme já mencionamos, os alemães preocupavam-se com a idéia de liberdade, enquanto as outras sociedades citadas procuravam exercê-la. Assim, em relação à Revolução Francesa, Hegel "viu desaparecer o velho mundo e está entusiasmada pelo novo espírito que faz assim seu aparecimento na cena do mundo: entusiasmo demasiado platônico" (Hyppolite, 1955, p. 45).

Em relação à Revolução Francesa pode-se ver a evolução de Hegel, antes da Fenomenologia, nos seguintes termos: em um primeiro momento assume uma posição reformista e em seguida contemplativa. Vivendo em uma sociedade feudal e monárquica, desejava introduzir reformas inspiradas pela Revolução. Hegel insiste no "poder das idéias". Em um segundo momento o encontramos crítico dos utopistas. Não mais quer reformar, mas compreender. Da inicial atitude reformista para uma atitude contemplativa. Somente um pouco mais tarde (aliás, com o sistema já "concebido"), na Fenomenologia do espírito tenta compreender a evolução que conduziu à Revolução e suas consequiências. Onde se lê "compreender a evolução" e "consequiências" leiase "Razão", "processo racional". Após a euforia inicial, a decepção; os alemães olham com desgosto o curso tomado pela Revolução. Para Hegel, o Estado deixa de ser considerado como um contrato; impõe-se aos indivíduos como seu destino. A pintura holandesa, no curso histórico das artes plásticas, antecipa no universo estético, no século XVII, os ideais sociais da Revolução Francesa. A tragédia grega, Antígone ou Édipo, expõe para a consciência a relação umbilical entre o destino do indivíduo e do Estado.

Pode-se ver nos três pontos que acabamos de considerar o palco teórico e histórico no qual Hegel atuou - as relações com o a Aufklärung e o Idealismo Alemão, a racionalização da religião, a Revolução Francesa -, pontos que podem ser reconhecidos como a inspiração inicial do sistema. A sequiência Kant-Fichte-Scelling-Hegel representa uma ordem "lógica" do desenvolvimento do Idealismo. Cumpre notar que o próprio Hegel é o responsável, em sua História da filosofia, pelo estabelecimento dessa sequiência na historiografia filosófica - a chamada "novíssima filosofia alemã". 
Sem dúvida, entre os quatro autores há pontos de contato - respiravam uma mesma atmosfera cultural e intelectual -, mas as inspirações são diferentes.

Desde cedo Hegel está preocupado com a história e a religião: expressões de uma condição real da sociedade. A Revolução Francesa é o estopim para pensar a questão da liberdade. Reconhece o homem efetivo como pertencente a uma determinada sociedade. O homem universal é uma abstração. Entretanto, lembremos que Hegel vive um momento em que predomina uma concepção universal do homem. Na medida em que não se reconhece o homem integrado em uma sociedade - a Cidade-Estado grega ou a religião como expressão da comunidade - ele deixa de ser um representante efetivo dessa sociedade e torna-se universal. O homem perde-se de si mesmo. Aí está a origem do conceito de alienação. A arte tem por "tarefa" manter o homem aderido ao real. Porque manifestação sensível da História e da Religião.

Conforme vimos, Hegel sofreu o impacto da subordinação da religião à razão. Tal submissão, atmosfera intelectual que respirou em seu período de formação, foi determinante no encaminhamento de suas concepções e da gestação do sistema e nelas do tratamento e do lugar reservado à obra de arte. O sentido que Hegel imprimiu à dialética - motor do sistema - encontrou no universo dos fenômenos artísticos uma ocasião impar para o desenvolvimento teórico. Na conjunção da história e da religião em suas preocupações da junventude, particularmente nos períodos de Frankfurt e Jena, encontramos os indícios do destino que a arte ganharia no sistema.

Ao longo das Lições sobre estética a consideração da obra de arte pela via da religião é extremamente freqüente. $\mathrm{O}$ universo artístico é visto como um estado de religiosidade: a celebração, o culto, as oferendas. A obra de arte confere materialidade aos rituais. Por outro lado, é lugar-comum reconhecer a estética hegeliana como uma história da arte; seja do ponto de vista lógico (a evolução do conceito de ideal quanto às relações entre a Idéia e o sensível), seja do ponto de vista da sucessão temporal das obras (o histórico). De maneira privilegiada, da ótica hegeliana, encontramos na Grécia clássica uma estreita relação entre a religião e a arte. A religião se manifesta pela arte. A própria arte é tida como atividade religiosa. Na arte o homem fala dos deuses e para os deuses. Entre uma e outra, dá-se uma espécie de reciprocidade. "Entre os gregos, por exemplo, a arte era a forma mais elevada de que o povo dispunha para representar os deuses e apreender conscientemente a verdade. Por isso os artistas e os poetas gregos vieram a ser os criadores dos deuses, quer dizer, deram ao povo uma representação determinada da ação, vida e operação do divino, ou seja, deram à religião um conteúdo determinado" (Hegel, 1989, p. 94).

O drama, antecâmara do sentimento religioso, é a origem da obra de arte. $\mathrm{O}$ drama, última etapa do desenvolvimento dialético das artes particulares, confere sentido - de modo retroativo - às demais artes. Dessa maneira, a obra de arte é, fundamentalmente, drama. Como tal expressa a realidade de maneira plena, pois são os conflitos que constituem o drama e, assim, nele a 
arte encontra a sua mais acabada realização dialética. O drama imita o modo de ser do homem no mundo; no drama se dá, da mesma maneira que no mundo, a razão na história. A estória está governada pela dialética do mesmo modo que governa a história. A poesia, de uma só vez arte do tempo e do espaço, reúne todas as etapas anteriores. Na poesia, a música e a palavra se unem para dar expressão ao que a escultura e a pintura representam de maneira limitada. Pode-se dizer que todas as artes convergem para o drama. De modo radical, para o espetáculo - um ritual, uma manifestação religiosa. Proveniente da religião, a arte caminha para a Religião. Dos desenhos de bizontes nas paredes de Lascaux à Aufkärung, à consciência de si que o Espírito tem de si mesmo.

É por meio da noção de "Espírito" que podemos reconhecer o liame ou a comunicação entre o jovem Hegel e o Hegel maduro. Lembremos esta indicação de Asveld: "De todos os conceitos que reatam os trabalhos de juventude aos escritos da maturidade, aquele que pode ser o guia mais seguro é o conceito hegeliano de espírito" (Asveld, 1953, p. 221).

A formação de Hegel se dá no último quartel do século XVIII quando o homem comum afirma-se dotado de valor pessoal e de dignidade - um cidadão. Mozarté uma boa ilustração que tem em Beethoven a sua confirmação.

Durante o período da juventude, de Stuttgart a Heidelberg, Hegel não trata de maneira explicita das manifestações artísticas; entretanto, na reflexão sobre aspectos da vida religiosa, bem como na consideração da religião grega, encontramos o embrião da concepção da arte como manifestação do Espírito Absoluto. O papel que as artes plásticas desempenharam no catolicismo e, de outro lado, no Protestantismo a música e o poema dispensadores de uma comunhão com Deus, já estão nas entrelinhas das posições do jovem Hegel. Por meio da religião, Hegel "descobre" a dialética e com ela a história. A principal referência é a religião grega, vista por Hegel como uma estetização do divino. A religião grega, ao mesmo tempo, é a história da Grécia. Em continuidade, tendo a religião grega como modelo, Hegel esboça uma concepção estética do cristianismo.

Entretanto, são as preocupações relativas à passagem do paganismo para o cristianismo - como reiteradamente se observou - que se dá a descoberta da história. E é essa mesma passagem que o alertou para o reconhecimento dialético das mutações históricas.

De maneira excepcional a história tem na arte o seu instrumento. A arte cristaliza os momentos vividos por uma comunidade - com seus valores e suas instituições - e os tornam presentes para a consciência dos membros dessa comunidade. Embora a ave de minerva alce o seu vôo ao entardecer, a arte exprime o sentido da atualidade. Mas, há que advertir que a arte não é tão somente depositária da história; como fazer, a arte exerce uma força no evolver histórico.

Conforme já observamos, pode-se dizer que a origem da reflexão de Hegel sobre a arte encontra-se na religião grega (que tem nas obras de arte a sua expressão) e na história uma vez que a considera, de uma lado como um 
momento do Absoluto (da totalidade divina), e de outro, como depositária das experiências histórico-religiosas de uma comunidade (e nelas, a vida moral, a vida ética, a vida pública). Por meio da arte pode-se inteligir a história e, por sua vez, a história ganha corpo nas manifestações artísticas.

Embora de maneira discreta, a arte aparece de início como um momento objetivo da vida religiosa. Em outros termos, como momento objetivo da totalidade divina, que na maturidade será concebida como Absoluto. Tal é o sentido que o jovem Hegel vê nas estátuas de Apolo ou de Zeus para a consciência do homem grego. Como momento objetivo da totalidade divina, a arte assume no oriente a presença "viva" da divindade, representação do universo divino no cristianismo e, por fim, expressão espiritual no protestantismo através da música e do poema. Dá-se um entrelaçamento da história e da religião que tem na arte o elemento unificador. Tal entrelaçamento o jovem Hegel já vislumbrara na religião grega, em sua estatuária, em seus concursos trágicos. Para o homem grego há uma fusão entre a história da comunidade e a tradição religiosa. Cabe à arte exprimi-las.

Sob certo aspecto, a arte morre porque se laiciza, porque deixa de exprimir o mundo religioso. A atividade e a criação artísticas prosseguem, mas as obras não mais detêm o alcance que possuíam; um bom exemplo é a pintura holandesa - embora detentora do maior valor estético, volta-se para o cotidiano, para o acidental. O valor estético passa a ser dimensionado pelo mundano. Os heróis, os semideuses, os santos, aqueles que portam um notável ou um terrível destino deixam de ser os grandes atores da arte. Entra em cena o homem comum. A arte como momento da "totalidade divina" já cumpriu sua missão. A poesia torna-se meditativa - antecâmara da filosofia e assim distancia-se de sua origem. O Hegel de Berlim irá imprimir uma correção a essas observações (que atribuímos ao Hegel de Jena) e, assim, reconhecer apenas a "morte lógica" da arte e afirmar a sua "vida histórica"- ou a sua eternidade, posto que manifestação do Espírito Absoluto. No Hegel da Enciclopédia, de maneira acabada, temos a concepção da arte como manifestação sensível da razão na história. 
VITOR, Knoll. History, religion and art. Tempo Social; Rev. Sociol. USP, S. Paulo, 8(2): 105-117, october 1996.

UNITERIMS:

history,

religion,

reason,

art.
ABSTRACT: Hegel's theoretical concerns during his formation period were linked to Aufklärung, to the relations between reason and religion and to political-ethical facts, referred to public life in classical Greece and the historical transformations in Europe related to the French Revolution. The multiple relations and implications of these theorical concerns implied the links between history and religion. The Hegel's thought about esthetics was originated from the same links like his conceptions of art. In the same way art for Hegel appeared as a perfect manifestation of the relation between history and religion.

\section{REFERÊNCIASBIBLIOGRÁFICAS}

Asveld, Paul. (1953) La pensée religieuse du jeune Hegel. Louvain, Desclée de Brouwer \& Cie./Publication Universitaires de Louvain.

BourgeOIS, Bernard. (1991) Éternité et historicité de l'esprit selon Hegel. Paris, Lib. Philosophique J. Vrin.

ChÂtelet, François. (1995) Hegel. Trad. Alda Porto. Rio de Janeiro, Jorge Zahar Editor.

DiLThey, Wilhelm. (1956) Hegel y el idealismo. Versión y epílogo Eugenio Ímaz. México, FCE.

Hegel, G. W. F. (1928) Vie de Jesus. Traduit et précédé d'une introduction D. D. Rosca. Paris, Lib. Universitaire J. Gamber.

(1948) L'esprit du christianisme et son destin. Trad. Jacques Martin. Paris, Lib. Philosophique J. Vrin.

. (1952) Premières publications: différence des systèmes philosophiques de Fichte et de Schelling - Foi et Savoir. Traduction, introduction et notes Marcel Méry. Paris, Lib. Philosophique J. Vrin.

. (1986) Filosofia real. Edición de José María Ripalda. Madrid, FCE.

. (1989) Estética. Vol. I. Vol. II (1991). Vol. III (1993). Trad. Raúl Gabás. Barcelona, Ediciones Península.

(1992) Fenomenologia do espírito. Trad. Paulo Meneses. Petrópolis, Vozes.

. (1995) Filosofia da história. Trad. Maria Rodrigues e Hans Harden. Brasília, Editora UnB.

HypPOLITE, Jean. (1948) Introduction a la philosophie de l'histoire de Hegel. Paris, Lib. Marcel Rivière et Cie.

. (1955) Études sur Marx et Hegel. Paris, Lib. Marcel Rivière. 
LALANDE. (1956) Vocabulaire technique et critique de la philosophie. Paris, PUF.

NiEL, Henri. (1945) De la médiation dans la philosophie de Hegel. Paris, Aubier.

PALmier, Jean-Michel. (1993) Hegel. Trad. Juan Jose Utrilla. Breviarios, México, FCE, 220.

WAHL, Jean. (1951) Le malheur de la conscience dans la philosophie de Hegel. Deuxième édition. Paris, PUF. 
VITOR, Knoll. História, religião e arte. Tempo Social; Rev. Sociol. USP, S. Paulo, 8(2): 105-117, outubro de 1996. 